\title{
Estrogen Receptor Family
}

National Cancer Institute

\section{Source}

National Cancer Institute. Estrogen Receptor Family. NCI Thesaurus. Code C17069.

Widely expressed human Estrogen Receptors (NR3 Family) are cytoplasmic hormoneactivated receptors that act as nuclear transcription factors composed of an $\mathrm{N}$-terminal transcription activation/modulation domain, a DNA-binding domain, and a C-terminal steroid-binding domain. Binding to DNA as a homo- or heterodimer, ESR interacts with NCOA3, NCOA5, and NCOA6 coactivators. Hormone-ESR complexes appear to recognize discrete upstream target ERE DNA sequences to regulate gene expression, cell proliferation, and differentiation. DNA-binding is lost in the absence of ligand. $(\mathrm{NCl})$ 